\title{
Genetic variation in CDH13 gene was associated with non-small cell lung cancer (NSCLC): A population-based case-control study
}

\author{
Yingfu Li ${ }^{1, *}$, Chuanyin $\mathrm{Li}^{2, *}$, Qianli $\mathrm{Ma}^{3}$, Yu Zhang ${ }^{2}$, Yueting $\mathrm{Yao}^{2}$, Shuyuan Liu ${ }^{2}$, \\ Xinwen Zhang ${ }^{2}$, Chao Hong ${ }^{2}$, Fang Tan ${ }^{1}$, Li Shi' ${ }^{2}$ and Yufeng $\mathrm{Yao}^{2}$ \\ ${ }^{1}$ Department of Geriatrics, The No.1 Affiliated Hospital of Kunming Medical University, Kunming, 650032, China \\ ${ }^{2}$ Institute of Medical Biology, Chinese Academy of Medical Sciences \& Peking Union Medical College, Kunming, 650118, China \\ ${ }^{3}$ Department of Thoracic Surgery, The No.3 Affiliated Hospital of Kunming Medical University, Kunming, 650118, China \\ "These authors contributed equally to this work
}

Correspondence to: Fang Tan, email: tanfang626@126.com

Li Shi, email: shili.imb@gmail.com

Yufeng Yao, email: leoyyf@gmail.com

Keywords: cadherin 13 (CDH13); single nucleotide polymorphisms (SNPs); non-small cell lung cancer (NSCLC); Chinese Han population

Received: October 11, 2017

Accepted: November 15, 2017

Published: December 05, 2017

Copyright: Li et al. This is an open-access article distributed under the terms of the Creative Commons Attribution License 3.0 (CC BY 3.0 ), which permits unrestricted use, distribution, and reproduction in any medium, provided the original author and source are credited.

\section{ABSTRACT}

Cadherin 13 (CDH13, T-cadherin, H-cadherin) has been identified as an antioncogene in various cancers. Recent studies have reported that downregulation of $\mathrm{H}$-cadherin in cancers is associated with $\mathrm{CDH13}$ promoter hypermethylation, which could be affected by the single nucleotide polymorphisms (SNPs) near CpG sites in the CDH13 promoter. In the current study, we investigated and analyzed the association of seven SNPs (rs11646213, rs12596316, rs3865188, rs12444338, rs4783244, rs12051272 and rs7195409) with non-small cell lung cancer (NSCLC) using logistic regression analysis. SNPs rs11646213, rs12596316, rs3865188 and rs12444338 are located in the promoter region, rs4783244 and rs12051272 are located in intron 1, and rs7195409 is located in intron 7. A total of 454 patients with NSCLC were placed into a NSCLC group and 444 healthy controls were placed into a control group, all participants were recruited to genotype the SNPs using Taqman assay. Our results showed that the allelic frequencies of rs11646213 were significantly different between NSCLC and control groups $(P=0.006)$. In addition, the association analysis of these SNPs stratified into NSCLC pathologic stages I+II and III+IV showed that the allelic frequencies rs7195409 had a significant difference between NSCLC pathologic stages I+II and III+IV $(P=0.006)$. Our results indicated that the rs11646213 and rs7195409 in CDH13 could be associated with NSCLC or its pathologic stages in the Chinese Han population.

\section{INTRODUCTION}

Lung cancer (LC) is the leading cause of cancer deaths in the world. In 2012, it is estimated that there were more than 1.8 million new cases $(13 \%$ of total cancer incidences) and almost 1.6 million deaths $(20 \%$ of total cancer mortality) [1]. In China, the incidence and mortality of $\mathrm{LC}$ are reported to be approximately 0.7 and 0.6 million cases, respectively in 2013 [2]. Non-small cell lung cancer (NSCLC) accounts for approximately $80 \%$ of all LC cases [3]. Recently, several studies have shown that Cadherin 13 (CDH13, T-cadherin, H-cadherin) functioned as an anti- oncogene and that its polymorphisms were associated with the development of different cancers [4-8].

Cadherin 13, a new member of the cadherin superfamily, is coded by the $C D H 13$ gene, which maps to chromosome 16q24.2 [9]. Cadherin proteins often contribute to the formation of intercellular junctions (e.g. $\mathrm{N}$ - and E-cadherin). Loss of cadherin expression has been described in many epithelial cancers and may play a role in tumor cell invasion and metastasis [10]. Recent studies have reported that Cadherin 13 functioned as an antioncogene in lung [4], breast [5], ovarian [6], bladder [11], esophageal [12] and gastric [13]. As an anti-oncogene, the 
downregulation of Cadherin 13 expression would promote cancer progression. In 2001, Toyooka et al. reported that Cadherin 13 expression is diminished in LC, and they demonstrated that the downregulation of Cadherin 13 might be due to hypermethylation in the $C D H 13$ promoter [14]. In addition, Putku et al. described that single nucleotide polymorphisms (SNPs) in CDH13 gene could affect the methylation of $\mathrm{CpG}$ sites in $\mathrm{CDH} 13$ gene [15]. Moreover, studies have shown that the SNPs in $\mathrm{CDH} 13$ gene could affect disease progression by influencing serum adiponectin levels $[7,8]$, and the serum adiponectin level was identified to be associated with LC [16]. Thus, the SNPs in CDH13 gene might be associated with LC through its correlation with $\mathrm{CDH} 13$ gene methylation and serum adiponectin level. Several studies have reported that SNPs in $C D H 13$ gene were associated with other diseases, such as colorectal cancer [17-19]. However, few study investigated the association between SNPs in CDH13 gene and NSCLC.

In the current study, we analyzed the association of seven SNPs (rs11646213, rs12596316, rs3865188, rs12444338, rs4783244, rs12051272 and rs7195409) in the $C D H 13$ gene with NSCLC and its pathologic stages in a Chinese Han population. SNPs rs11646213, rs12596316, rs3865188 and rs12444338 are located in the promoter, rs4783244 and rs12051272 are located in intron 1, and rs 7195409 is located in intron 7.

\section{RESULTS}

\section{Subject characteristics}

Table 1 lists the clinical characteristics of the subjects in the present study. There were no significant differences in age or gender between the NSCLC and control groups $(P>0.05)$. In the NSCLC group, there were 283 patients with adenocarcinoma (AC), 163 patients with squamous cell carcinoma (SCC), and 8 patients with adenocarcinoma and squamous cell carcinoma (AC + SCC). There were 73 patients in pathological stage I, 73 patients in stage II, 163 patients in stage III and 145 patients in stage IV.

\section{Association of the seven SNPs in $\mathrm{CDH} 13$ with NSCLC}

The allelic and genotypic frequencies for rs11646213, rs12596316, rs3865188, rs12444338, rs4783244, rs 12051272 and rs7195409 in the NSCLC and control groups are listed in Table 2. These SNPs were all in Hardy-Weinberg equilibrium (HWE) for the NSCLC and control groups $(P>0.05)$. The logistic regression analysis showed that the allelic frequencies of rs11646213 were significantly different between NSCLC group and the control group $(P=0.006)$, which suggested that T allele of re11646213 had an increased effect on NSCLC risk after adjusted for gender and age $(\mathrm{OR}=1.409 ; 95 \% \mathrm{CI}: 1.105$
1.798). However, the allelic and genotypic frequencies of the other SNPs were not significantly different between the NSCLC and control groups $(P>0.007)$.

\section{Model of inheritance analysis of the seven SNPs in $\mathrm{CDH} 13$ gene with NSCLC}

Logistic regression analysis was used in model of inheritance analysis to evaluate the association between genotypes of the SNPs and NSCLC. The Akaike information criterion (AIC) and Bayesian information criterion (BIC) were calculated to determining the best fit inheritance model, which possesses the smallest AIC and $\mathrm{BIC}$ values. The best inheritance model with the lowest AIC and BIC for rs11646213 was the recessive model ( $P$ $=0.004$, after adjusted for gender and age) (Table 3 ). In this model, the T/T genotype of rs11646213 conferred more risk of NSCLC $(\mathrm{OR}=3.26$; 95\%CI:1.41-7.56). In addition, no significant differences for other SNPs were found between NSCLC and control groups in the model of inheritance analysis $(P>0.007)$ (data not shown).

\section{Linkage disequilibrium (LD) and haplotype analysis of the seven SNPs in $\mathrm{CDH} 13$ gene}

Significant LD values ( $D^{>}>0.85$ and $R^{2}>0.7$ ) among five of the seven SNPs (except for rs7195409 and rs11646213) were found in all individuals (Table 4). Based on the LD result, we constructed the haplotypes of the five SNPs (rs12596316, rs3865188, rs12444338, rs4783244 and rs12051272) and analyzed the difference in the haplotype frequencies (frequency more than 3\%) between the NSCLC and control groups. Two main haplotypes were observed, and the frequencies of rs12596316A-rs3865188A-rs12444338Grs4783244G-12051272G and rs12596316G-rs3865188Trs 12444338T-rs4783244T-12051272T were 58.0\% and $33.7 \%$ in NSCLC and $59.8 \%$ and $30.6 \%$ in control groups. None of the haplotypes were significantly different in the NSCLC and control groups $(P>0.007)$ (Table 5).

\section{Association analysis of seven SNPs in $\mathrm{CDH} 13$ gene with different NSCLC pathologic stages}

Table 6 lists the comparisons of the genotypic and the allelic distribution of the seven SNPs in different NSCLC pathologic stages (I+II and III+IV). The allelic frequencies of rs12444338, rs4783244, rs12051272 and the genotypic frequencies of rs7195409 just only exhibited a trend of significant difference between NSCLC I+II and III+IV patients $(P=0.011,0.018$, 0.024 and 0.013 respectively). However, the allelic frequencies of rs7195409 showed significant difference between NSCLC I+II and III+IV patients after Bonferroni correction $(P=0.006)$. We also conducted an inheritance model analysis to identify the best fit model of these four SNPs to compare the differences between NSCLC I+II 
Table 1: Clinical characteristics of the subjects enrolled in the present study

\begin{tabular}{lccc}
\hline & NSCLC & Control & $P$-value \\
\hline N & 454 & 444 & 0.084 \\
Age (years) & $55.99 \pm 10.76$ & $54.82 \pm 9.54$ & $296 / 148$ \\
Sex (M/F) & $307 / 147$ & \\
Adenocarcinoma (AC) & 283 & \\
Squamous cell carcinoma (SSC) & 163 & \\
Adenocarcinoma and Squamous cell carcinoma (AC+SSC) & 8 & \\
Clinical stage & & \\
I & 73 & \\
II & 73 & \\
III & 163 & \\
IV & 145 & \\
\hline
\end{tabular}

and III+IV pathologic stages. The results showed that the best fit model for rs 12444338 , rs4783244 and rs 12051272 was the log-additive model $(P=0.004,0.006$ and 0.005 respectively), and the best fit model for rs7195409 was the dominant model $(P=0.001)$ (Table 7).

\section{DISCUSSION}

Although persistent work has been done for the prevention and therapy of NSCLC, it remains the most common cancer in the world [20], and annual incidence and mortality has been trending upward [21]. Recently, studies have shown that polymorphisms in $\mathrm{CDH} 13$ gene could lead to aberrant methylation of the $\mathrm{CDH} 13$ promoter and influence plasma adiponectin level which have been demonstrated to be as biomarkers of LC [2224]. However, they did not evaluate the association of SNPs in CDH13 gene with LC [22-24]. In current study, we investigated the relationship between seven SNPs in CDH13 gene and NSCLC.

Adiponectin is an adipose tissue-secreted protein that acts as an endogenous insulin sensitizer by binding to insulin receptors [25]. Data from recent studies proved that lower adiponectin levels are associated with an increased risk of endometrial cancer [26], renal cancer [27], colon cancer [28] and breast cancer [29]. In 2016, Wei et al. performed a meta-analysis on circulating adiponectin levels in various malignancies and found that decreased adiponectin levels are associated with the risk of various cancers, including LC [30]. Several studies revealed that SNPs (rs12444338, rs3865188, rs4783244, rs12051272, rs12596316, rs11646213, rs7195409) in CDH13 gene determined plasma adiponectin levels in multi-ethnic populations [31-34]. In 2017, Nicolas et al. reported that rs11646213 was correlated with plasma adiponectin levels [34]. They observed that the A allele of rs11646213 was significantly associated with lower plasma adiponectin levels in Insulin Resistance Syndrome in French populations. However, this result was in contradiction with results of the present study, where our results showed that the $\mathrm{T}$ allele of rs11646213 might be the risk factor for NSCLC, which should be associated with lower plasma adiponectin levels. Moreover, Ling et al. found that rs7195409 was associated with adiponectin levels in Europeans $\left(P=2.0 \times 10^{-5}\right)$ [35], while in Filipino women, Wu et al. [31] did not find any association between rs7195409 and adiponectin levels that was coincident with the current study (no association between this SNP and NSCLC). One of the reasons for the discrepancies might be the two different study populations (European and Asian) with different genetic backgrounds. The A allele of rs11646213 accounts for approximately $42 \%$ as the minor allele in the European population, while the same allele accounts for approximately $82 \%$ as the major allele in the East Asian population (http://asia.ensembl.org/Homo sapiens/Variation/Population?db=core; $\mathrm{r}=16: 82608546-$ 82609546; $=\mathrm{rs} 11646213 ; \mathrm{vdb}=$ variation; $\mathrm{vf}=6808482$ ).

Another reason could be that different diseases have different molecular mechanisms. The complex pathogenic mechanisms could make the same SNP play different roles in the different diseases. However, the plasma adiponectin levels were not measured in the current study, thus, we could not evaluate the association between genetic data, adiponectin levels and NSCLC risk. Whether rs11646213 was associated with NSCLC through influencing the plasma adiponectin levels in the current study population requires functional studies to be clarified in different diseases.

In 1996, Lee et al. found that the CDH13 transcript was undetectable in all examined breast cancer and most other cancer cell lines, supporting its role as a tumor suppressor [36]. Then, Zhong et al. reported that the loss of Cadherin 13 expression was associated with tumorigenicity in nude mice transplanted with NSCLC tumors [37]. Moreover, Lee et al. and Chan et al. reported that the introduction and overexpression of Cadherin 13 in human breast carcinoma and hepatocellular carcinoma cell lines markedly inhibited tumor growth and invasiveness 
Table 2: The association analysis between the seven SNPs in CDH13 gene and NSCLC (After adjusted for gender and age)

\begin{tabular}{|c|c|c|c|c|c|c|c|c|}
\hline \multirow{2}{*}{$\begin{array}{c}\text { SNPs } \\
\text { rs11646213 }\end{array}$} & \multicolumn{3}{|c|}{ Genotypes (n,\%) } & \multirow[t]{2}{*}{$P$-value* } & \multicolumn{2}{|c|}{ Alleles (n,\%) } & \multirow[t]{2}{*}{$P$-value* } & \multirow[t]{2}{*}{ OR $(95 \% C I)$} \\
\hline & $\mathrm{A} / \mathrm{A}$ & $\mathrm{A} / \mathrm{T}$ & $\mathrm{T} / \mathrm{T}$ & & $\mathrm{T}$ & A & & \\
\hline NSCLC & $292(64.3 \%)$ & $138(30.4 \%)$ & $24(5.3 \%)$ & \multirow{2}{*}{0.017} & $186(20.5 \%)$ & $722(79.5 \%)$ & \multirow{2}{*}{0.006} & \multirow{2}{*}{$1.409(1.105-1.798)$} \\
\hline Control & $316(71.2 \%)$ & $118(26.6 \%)$ & $10(2.3 \%)$ & & $138(15.5 \%)$ & $750(84.5 \%)$ & & \\
\hline rs12596316 & $\mathrm{A} / \mathrm{A}$ & $\mathrm{A} / \mathrm{G}$ & $\mathrm{G} / \mathrm{G}$ & & G & A & & \\
\hline NSCLC & $169(37.2 \%)$ & $217(47.8 \%)$ & $68(15.0 \%)$ & \multirow{2}{*}{0.131} & $353(38.9 \%)$ & $55561.1 \%)$ & \multirow{2}{*}{0.256} & \multirow{2}{*}{$1.118(0.923-1.354)$} \\
\hline Control & $192(43.2 \%)$ & $184(41.4 \%)$ & $68(15.3 \%)$ & & $320(36.0 \%)$ & $568(64.0 \%)$ & & \\
\hline rs3865188 & $\mathrm{A} / \mathrm{A}$ & $\mathrm{A} / \mathrm{T}$ & $\mathrm{T} / \mathrm{T}$ & & $\mathrm{T}$ & $\mathrm{A}$ & & \\
\hline NSCLC & $168(37.0 \%)$ & $218(48.0 \%)$ & $68(15.0 \%)$ & \multirow{2}{*}{0.242} & $354(39.0 \%)$ & $554(61.0 \%)$ & \multirow{2}{*}{0.311} & \multirow{2}{*}{$1.104(0.912-1.337)$} \\
\hline Control & $187(42.1 \%)$ & $190(42.8 \%)$ & $67(15.1 \%)$ & & $324(36.5 \%)$ & $564(63.5 \%)$ & & \\
\hline rs12444338 & $\mathrm{G} / \mathrm{G}$ & $\mathrm{G} / \mathrm{T}$ & $\mathrm{T} / \mathrm{T}$ & & $\mathrm{T}$ & G & & \\
\hline NSCLC & $178(39.2 \%)$ & $211(46.5 \%)$ & $65(14.3 \%)$ & \multirow{2}{*}{0.288} & $341(37.6 \%)$ & $567(62.4 \%)$ & \multirow{2}{*}{0.301} & \multirow{2}{*}{$1.107(0.913-1.343)$} \\
\hline Control & $196(44.1 \%)$ & $185(41.7 \%)$ & $63(14.2 \%)$ & & $311(35.0 \%)$ & $577(65.0 \%)$ & & \\
\hline rs4783244 & $\mathrm{G} / \mathrm{G}$ & $\mathrm{G} / \mathrm{T}$ & $\mathrm{T} / \mathrm{T}$ & & $\mathrm{T}$ & G & & \\
\hline NSCLC & $173(38.1 \%)$ & $212(46.7 \%)$ & $69(15.2 \%)$ & \multirow{2}{*}{0.536} & $350(38.5 \%)$ & $558(61.5 \%)$ & \multirow{2}{*}{0.442} & \multirow{2}{*}{$1.078(0.890-1.306)$} \\
\hline Control & $185(41.7 \%)$ & $193(43.5 \%)$ & $66(14.9 \%)$ & & $325(36.6 \%)$ & $563(63.4 \%)$ & & \\
\hline rs12051272 & $\mathrm{G} / \mathrm{G}$ & $\mathrm{G} / \mathrm{T}$ & $\mathrm{T} / \mathrm{T}$ & & $\mathrm{T}$ & G & & \\
\hline NSCLC & $189(41.6 \%)$ & $201(44.3 \%)$ & $64(14.1 \%)$ & \multirow{2}{*}{0.544} & $329(36.2 \%)$ & $579(63.8 \%)$ & \multirow{2}{*}{0.344} & \multirow{2}{*}{$1.099(0.904-1.334)$} \\
\hline Control & $201(45.3 \%)$ & $185(41.7 \%)$ & $58(13.1 \%)$ & & $301(33.9 \%)$ & $587(66.1 \%)$ & & \\
\hline rs7195409 & $\mathrm{A} / \mathrm{A}$ & $\mathrm{A} / \mathrm{G}$ & $\mathrm{G} / \mathrm{G}$ & & G & A & & \\
\hline NSCLC & $314(69.3 \%)$ & $129(28.5 \%)$ & $10(2.2 \%)$ & \multirow{2}{*}{0.436} & $149(16.4 \%)$ & $757(83.6 \%)$ & \multirow{2}{*}{0.176} & \multirow{2}{*}{$1.195(0.923-1.546)$} \\
\hline Control & $325(73.2 \%)$ & $110(24.8 \%)$ & $9(2.0 \%)$ & & $128(14.4 \%)$ & $760(85.6 \%)$ & & \\
\hline
\end{tabular}

${ }^{\bar{x}}$ Statistical significant threshold was set at $P<0.007(0.05 / 7)$ determined by Bonferroni correction.

$[38,39]$. Thus, Cadherin 13 was considered an important tumor suppressor in colorectal, lung, breast, ovarian and bladder cancers [40-43]. Aberrant methylation of tumor suppressor genes leads to tumorigenesis, due to the silencing of suppressors [44]. The aberrant methylation of $\mathrm{CpG}$ islands in the $\mathrm{CDH} 13$ promoter might lead to aberrant gene expression and further promote tumor progression. This association was reported in many cancers, such as hepatocellular carcinoma, cervical neoplasia and breast cancer [45-47]. In 2016, Jin et al. reported that aberrant methylation of the $\mathrm{CDH} 13$ promoter is associated with tumor progress in primary NSCLC [48]. Moreover, Shi et al. showed that genetic variability extensively influenced DNA methylation [49], and polymorphisms in the $\mathrm{CpG}$ sites of the $\mathrm{CDH} 13$ promoter were associated with aberrant methylation of the $\mathrm{CDH} 13$ promoter $[15,50]$. In the current study, our results showed that the frequency of rs 11646213 in the $C D H 13$ promoter was significantly different between NSCLC and control groups at the allelic and genotypic level. Thus, we could deduce that rs 11646213 might be associated with NSCLC through affecting the $\mathrm{CDH} 13$ promoter methylation status. However, the other SNPs allelic frequency in the $\mathrm{CDH} 13$ promoter, such as rs12596316, rs3865188 and rs12444338, was not significantly different between NSCLC and control groups. The reason for the discrepancy might be the linkage disequilibrium (LD) of these SNPs, and rs 11646213 was not in LD with other SNPs in the $C D H 13$ promoter (Table 4).

On the NSCLC pathologic level, rs11646213 showed no association with NSCLC pathologic stages. It was interesting that rs12444338, rs4738244 and rs12051272 SNPs, which are in different regions of $\mathrm{CDH} 13$ gene showed a correlation trend with NSCLC $(P=0.011,0.018$ and 0.024 , respectively), which might be due to the fact that rs12444338 was in LD with the rs4783244 and rs12051272 (Table 4). In addition, Morisaki et al. reported that rs4783244 and rs12051272, which are located in $C D H 13$ intron 1, were in LD with rs 12444338 located in the promoter because of a $30-\mathrm{kb}$ haplotype block from the $\mathrm{CDH} 13$ promoter region to the first intron [7]. Thus, rs4783244, rs12051272 and rs12444338 exhibited a similar trend of association with NSCLC pathologic stages, despite that these SNPs are located in different regions of the $\mathrm{CDH} 13$ gene. In the current study, we found that rs 7195409 , located in $C D H 13$ intron 7, was associated with NSCLC pathologic stages $(P=0.006)$. The model of inheritance analysis showed that rs4783244, rs12051272, rs12444338 and rs7195409 were all associated with pathologic stages of NSCLC ( $P=$ $0.004,0.006,0.005$ and 0.001 , respectively). The best fit model of rs4783244, rs12051272 and rs12444338 was log- 
Table 3: Different inheritance model analyses of rs11646213 in CDH13 between NSCLC and control groups (After adjusted for gender and age)

\begin{tabular}{lccccccc}
\hline Models & Genotypes & Control (n, \%) & NSCLC (n, \%) & OR (95\% CI) & $\boldsymbol{P}_{\text {-value* }}$ & AIC & BIC \\
\hline Codominant & $\mathrm{A} / \mathrm{A}$ & $316(71.2 \%)$ & $292(64.3 \%)$ & 1.00 & & & \\
& $\mathrm{~A} / \mathrm{T}$ & $118(26.6 \%)$ & $138(30.4 \%)$ & $1.16(0.84-1.61)$ & 0.011 & 1207.6 & 1490.8 \\
& $\mathrm{~T} / \mathrm{T}$ & $10(2.2 \%)$ & $24(5.3 \%)$ & $3.43(1.47-8.00)$ & & & \\
Dominant & $\mathrm{A} / \mathrm{A}$ & $316(71.2 \%)$ & $292(64.3 \%)$ & 1.00 & & & \\
& $\mathrm{~A} / \mathrm{T}-\mathrm{T} / \mathrm{T}$ & $128(28.8 \%)$ & $162(35.7 \%)$ & $1.30(0.95-1.77)$ & 0.110 & 1212.0 & 1490.4 \\
Recessive & $\mathrm{A} / \mathrm{A}-\mathrm{A} / \mathrm{T}$ & $434(97.8 \%)$ & $430(94.7 \%)$ & 1.00 & & & \\
& $\mathrm{~T} / \mathrm{T}$ & $10(2.2 \%)$ & $24(5.3 \%)$ & $3.26(1.41-7.56)$ & 0.004 & 1206.4 & 1484.8 \\
Overdominant & $\mathrm{A} / \mathrm{A}-\mathrm{T} / \mathrm{T}$ & $326(73.4 \%)$ & $316(69.6 \%)$ & 1.00 & & & \\
& $\mathrm{~A} / \mathrm{T}$ & $118(26.6 \%)$ & $138(30.4 \%)$ & $1.08(0.78-1.49)$ & 0.640 & 1214.4 & 1492.8 \\
Log-additive & --- & --- & -- & $1.38(1.05-1.81)$ & 0.019 & 1209.1 & 1487.5 \\
\hline
\end{tabular}

"Statistical significant threshold was set at $P<0.007(0.05 / 7)$ determined by Bonferroni correction.

additive, but the best fit model of rs 7195409 was dominant (Table 7). This difference could be because rs 7195409 was not in LD with rs4783244, rs12051272 and rs12444338. The rs7195409 SNP was located in CDH13 intron 7, and its surrounding nucleotide sequence does not match the known transcription factor binding site or miRNA targeted sequence. Thus, it is likely that rs7195409 is an independent marker or candidate SNP for NSCLC development. In addition, other SNPs surrounding or in LD with rs7195409 might be the real candidate SNPs that influence and play important roles in the development of NSCLC.

\section{MATERIALS AND METHODS}

\section{Ethics statement}

The current study was conducted in accordance with the guidelines and principles declared in the Declaration of Helsinki and approved by the Institutional Review Boards of the No.1 Affiliated Hospital of Kunming Medical University. All participants provided written informed consent.

\section{Subjects}

A total of 454 patients (307 males and 147 females) diagnosed with NSCLC at the No.1 Affiliated Hospital of Kunming Medical University from July 2012 to May 2014 were recruited. The histological types were identified according to the World Health Organization (WHO 2004) classifications. The International System for Staging Lung Cancer was used to determine the lung cancer pathologic stages [51]. According to the pathomorphological reports, the NSCLC patients were divided into AC, SCC, and AC+SCC. Subjects with oncotherapy history or other cancers were excluded from the current study. In addition, individuals with hypertension, coronary heart disease and diabetes were also excluded from the current study. Clinical characteristics, such as gender, age, family history of cancer, and histological type of cancer, were collected. A total of 444 healthy individuals (296 males and 148 females) who had no family history of NSCLC were recruited from a population undergoing routine health checkups at the same hospitals. As subjects with a family history of cancer were excluded from control group, individuals who had family history of cancer were also removed from NSCLC group. All participants self-reported as Han and lived roughly within Yunnan Province, southwest of China.

\section{SNP genotyping using the TaqMan assay method}

Genomic DNA of the subjects was extracted from peripheral lymphocytes using the QIAamp Blood Mini Kit (Qiagen, Hilden, Germany). Seven SNPs in the CDH13 gene, namely, rs11646213, rs12596316, rs3865188, rs12444338, rs4783244, rs12051272 and rs7195409, were selected and genotyped through PCR amplification using a TaqMan assay. The TaqMan assays (primers and probes) were designed and produced by Applied Biosystems (Foster City, CA, USA). The assay ID for each SNP were rs 11646213 (C_10076324_10), rs12596316 (C 3110327410$), \quad$ rs3865188

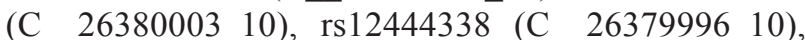
rs4783244 (C 10076301 10), rs12051272 (C_31103269_10) and rs7195409 (C__1178915_10). The PCR reaction was performed in 384-well plates using a QuantStudio 6 Flex Fast Real-Time PCR system according to the manufacture instructions. A 5- $\mu$ l reaction system consisting of $2.5 \mu 12 \times$ TaqMan Master Mix, $0.125 \mu 140 \times$ Primer and TaqMan Probe (FAM VIC) dye mix, $1.375 \mu \mathrm{lddH_{2 }} \mathrm{O}$, and $1 \mu 1$ template DNA (substituted by equivalent $\mathrm{ddH}_{2} \mathrm{O}$ in negative control) was amplified using PCR cycle conditions: $95^{\circ} \mathrm{C}$ for $10 \mathrm{~min}$; PCR stage $92^{\circ} \mathrm{C}$ for $10 \mathrm{~s}$ and $60^{\circ} \mathrm{C}$ for $1 \mathrm{~min}$ repeated in 40 
Table 4: Linkage disequilibrium analysis of the seven SNPs in $\mathrm{CDH} 13$ gene

\begin{tabular}{lcccccc}
\hline D'/R2 value & rs12596316 & rs3865188 & rs12444338 & rs4783244 & rs12051272 & rs7195409 \\
\hline rs11646213 & $0.667 / 0.059$ & $0.705 / 0.066$ & $0.670 / 0.056$ & $0.677 / 0.061$ & $0.848 / 0.086$ & $0.021 / 0.000$ \\
rs12596316 & - & $\mathbf{0 . 9 3 7 / 0 . 8 6 7}$ & $\mathbf{0 . 9 1 4 / 0 . 7 9 5}$ & $\mathbf{0 . 8 6 7 / 0 . 7 4 9}$ & $\mathbf{0 . 9 1 8 / 0 . 7 6 0}$ & $0.010 / 0.000$ \\
rs3865188 & - & - & $\mathbf{0 . 9 6 7 / 0 . 8 7 9}$ & $\mathbf{0 . 9 1 0 / 0 . 8 2 2}$ & $\mathbf{0 . 9 6 3 / 0 . 8 2 6}$ & $0.012 / 0.000$ \\
rs12444338 & - & - & - & $\mathbf{0 . 9 7 2 / 0 . 8 9 5}$ & $\mathbf{0 . 9 6 7 / 0 . 8 8 6}$ & $0.044 / 0.000$ \\
rs4783244 & - & - & - & - & $\mathbf{0 . 9 7 9 / 0 . 8 6 0}$ & $0.052 / 0.000$ \\
rs12051272 & - & - & - & - & - & $0.009 / 0.000$ \\
\hline
\end{tabular}

Table 5: Haplotype analysis of the five SNPs (rs12596316, rs3865188, rs12444338, rs4783244 and rs12051272) in $\mathrm{CDH} 13$ gene

\begin{tabular}{lllll}
\hline Haplotypes & NSCLC (n, \%) & Control (n, \%) & $\boldsymbol{P}_{\text {-value }}$ & OR(95\%CI) \\
\hline A A G G G $^{*}$ & $526.47(58.0 \%)$ & $531.23(59.8 \%)$ & 0.221 & $0.881(0.719 \sim 1.079)$ \\
G T T T T* $^{*}$ & $306.14(33.7 \%)$ & $272.15(30.6 \%)$ & 0.221 & $1.135(0.927 \sim 1.390)$
\end{tabular}

"Statistical significant threshold was set at $P<0.007$ (0.05/7) determined by Bonferroni correction.

Table 6: The association analysis between the seven SNPs in $C D H 13$ and NSCLC pathologic stages I+II and III+IV (After adjusted for gender and age)

\begin{tabular}{|c|c|c|c|c|c|c|c|c|}
\hline \multirow{2}{*}{$\begin{array}{c}\text { SNPs } \\
\text { rs11646213 }\end{array}$} & \multicolumn{3}{|c|}{ Genotypes (n, \%) } & \multirow[t]{2}{*}{$P$-value ${ }^{*}$} & \multicolumn{2}{|c|}{ Alleles (n, \%) } & \multirow[t]{2}{*}{$P$-value ${ }^{*}$} & \multirow[t]{2}{*}{ OR(95\%CI) } \\
\hline & $\mathrm{A} / \mathrm{A}$ & $\mathrm{A} / \mathrm{T}$ & $\mathrm{T} / \mathrm{T}$ & & A & $\mathrm{T}$ & & \\
\hline $\mathrm{III}+\mathrm{IV}$ & $193(62.7 \%)$ & $98(31.8 \%)$ & $17(5.5 \%)$ & \multirow{2}{*}{0.578} & $484(78.6 \%)$ & $132(21.4 \%)$ & \multirow{2}{*}{0.313} & \multirow{2}{*}{$1.199(0.842-1.707)$} \\
\hline $\mathrm{I}+\mathrm{II}$ & $99(67.8 \%)$ & $40(27.4 \%)$ & $7(4.8 \%)$ & & $238(81.5 \%)$ & $54(18.5 \%)$ & & \\
\hline rs 12596316 & $\mathrm{~A} / \mathrm{A}$ & $\mathrm{A} / \mathrm{G}$ & $\mathrm{G} / \mathrm{G}$ & & A & G & & \\
\hline $\mathrm{III}+\mathrm{IV}$ & $108(35.1 \%)$ & $151(49.0 \%)$ & $49(15.9 \%)$ & \multirow{2}{*}{0.358} & $367(59.6 \%)$ & $249(40.4 \%)$ & \multirow{2}{*}{0.137} & \multirow{2}{*}{$1.247(0.932-1.668)$} \\
\hline $\mathrm{I}+\mathrm{II}$ & $61(41.8 \%)$ & $66(45.2 \%)$ & $19(13.0 \%)$ & & $188(64.4 \%)$ & $104(35.6 \%)$ & & \\
\hline rs3865188 & $\mathrm{A} / \mathrm{A}$ & $\mathrm{A} / \mathrm{T}$ & $\mathrm{T} / \mathrm{T}$ & & A & $\mathrm{T}$ & & \\
\hline III+IV & $106(34.4 \%)$ & $151(49.0 \%)$ & $51(16.6 \%)$ & \multirow{2}{*}{0.171} & $363(58.9 \%)$ & $253(41.1 \%)$ & \multirow{2}{*}{0.050} & \multirow{2}{*}{$1.339(1.001-1.792)$} \\
\hline $\mathrm{I}+\mathrm{II}$ & $62(42.5 \%)$ & $67(45.9 \%)$ & $17(11.6 \%)$ & & $191(65.4 \%)$ & $101(34.6 \%)$ & & \\
\hline rs12444338 & $\mathrm{G} / \mathrm{G}$ & $\mathrm{G} / \mathrm{T}$ & $\mathrm{T} / \mathrm{T}$ & & G & $\mathrm{T}$ & & \\
\hline $\mathrm{III}+\mathrm{IV}$ & $110(35.7 \%)$ & $148(48.1 \%)$ & $50(16.2 \%)$ & \multirow{2}{*}{0.051} & $368(59.7 \%)$ & $248(40.3 \%)$ & \multirow{2}{*}{0.011} & \multirow{2}{*}{$1.465(1.090-1.969)$} \\
\hline $\mathrm{I}+\mathrm{II}$ & $68(46.6 \%)$ & $63(43.2 \%)$ & $15(10.3 \%)$ & & $199(68.2 \%)$ & $93(31.8 \%)$ & & \\
\hline rs4783244 & $\mathrm{G} / \mathrm{G}$ & $\mathrm{G} / \mathrm{T}$ & $\mathrm{T} / \mathrm{T}$ & & G & $\mathrm{T}$ & & \\
\hline $\mathrm{III}+\mathrm{IV}$ & $107(34.7 \%)$ & $149(48.4 \%)$ & $52(16.9 \%)$ & \multirow{2}{*}{0.074} & $363(58.9 \%)$ & $253(41.1 \%)$ & \multirow{2}{*}{0.018} & \multirow{2}{*}{$1.426(1.063-1.913)$} \\
\hline $\mathrm{I}+\mathrm{II}$ & $66(45.2 \%)$ & $63(43.2 \%)$ & $17(11.6 \%)$ & & $195(66.8 \%)$ & $97(33.2 \%)$ & & \\
\hline rs12051272 & $\mathrm{G} / \mathrm{G}$ & $\mathrm{G} / \mathrm{T}$ & $\mathrm{T} / \mathrm{T}$ & & G & $\mathrm{T}$ & & \\
\hline $\mathrm{III}+\mathrm{IV}$ & $118(38.3 \%)$ & $142(46.1 \%)$ & $48(15.6 \%)$ & \multirow{2}{*}{0.093} & $378(61.4 \%)$ & $238(38.6 \%)$ & \multirow{2}{*}{0.024} & \multirow{2}{*}{$1.410(1.047-1.899)$} \\
\hline $\mathrm{I}+\mathrm{II}$ & $71(48.6 \%)$ & $59(40.4 \%)$ & $16(11.0 \%)$ & & $201(68.8 \%)$ & $91(31.2 \%)$ & & \\
\hline rs7195409 & $\mathrm{A} / \mathrm{A}$ & $\mathrm{A} / \mathrm{G}$ & $\mathrm{G} / \mathrm{G}$ & & A & G & & \\
\hline $\mathrm{III}+\mathrm{IV}$ & $227(73.7 \%)$ & $75(24.4 \%)$ & $6(1.9 \%)$ & \multirow{2}{*}{0.013} & $529(85.9 \%)$ & $87(14.1 \%)$ & \multirow{2}{*}{0.006} & \multirow{2}{*}{$0.599(0.416-0.861)$} \\
\hline $\mathrm{I}+\mathrm{II}$ & $87(60.0 \%)$ & $54(37.2 \%)$ & $4(2.8 \%)$ & & $228(78.6 \%)$ & $62(21.4 \%)$ & & \\
\hline
\end{tabular}

${ }^{*}$ Statistical significant threshold was set at $P<0.007(0.05 / 7)$ determined by Bonferroni correction 
Table 7: Different inheritance models analysis of rs12444338, rs4783244, rs12051272 and rs7195409 in $\mathrm{CDH} 13$ gene between $\mathrm{I}+\mathrm{II}$ and III+IV pathologic stages (After adjusted for gender and age)

\begin{tabular}{|c|c|c|c|c|c|c|c|c|}
\hline SNPs & Models & Genotypes & I+II $(\mathbf{n}, \%)$ & III+IV (n, \%) & OR $(95 \%$ CI $)$ & $P$-value ${ }^{*}$ & AIC & BIC \\
\hline \multirow[t]{10}{*}{ rs12444338 } & \multirow[t]{3}{*}{ Codominant } & $\mathrm{G} / \mathrm{G}$ & $68(46.6 \%)$ & $110(35.7 \%)$ & 1.00 & \multirow{3}{*}{0.012} & \multirow{3}{*}{600.8} & \multirow{3}{*}{831.4} \\
\hline & & $\mathrm{G} / \mathrm{T}$ & $63(43.1 \%)$ & $148(48.0 \%)$ & $1.41(0.87-2.30)$ & & & \\
\hline & & $\mathrm{T} / \mathrm{T}$ & $15(10.3 \%)$ & $50(16.2 \%)$ & $3.10(1.41-6.82)$ & & & \\
\hline & \multirow[t]{2}{*}{ Dominant } & $\mathrm{G} / \mathrm{G}$ & $68(46.6 \%)$ & $110(35.7 \%)$ & 1.00 & \multirow{2}{*}{0.031} & \multirow{2}{*}{603.0} & \multirow{2}{*}{829.5} \\
\hline & & G/T-T/T & $78(53.4 \%)$ & $198(64.3 \%)$ & $1.66(1.05-2.65)$ & & & \\
\hline & \multirow[t]{2}{*}{ Recessive } & G/G-G/T & $131(89.7 \%)$ & $258(83.8 \%)$ & 1.00 & \multirow{2}{*}{0.009} & \multirow{2}{*}{600.7} & \multirow{2}{*}{827.2} \\
\hline & & $\mathrm{T} / \mathrm{T}$ & $15(10.3 \%)$ & $50(16.2 \%)$ & $2.56(1.22-5.38)$ & & & \\
\hline & \multirow[t]{2}{*}{ Overdominant } & G/G-T/T & $83(56.9 \%)$ & $160(52.0 \%)$ & 1.00 & \multirow{2}{*}{0.740} & \multirow{2}{*}{607.5} & \multirow{2}{*}{834.0} \\
\hline & & $\mathrm{G} / \mathrm{T}$ & $63(43.1 \%)$ & $148(48.0 \%)$ & $1.08(0.69-1.70)$ & & & \\
\hline & Log-additive & --- & --- & --- & $1.64(1.16-2.31)$ & 0.004 & 599.5 & 826.0 \\
\hline \multirow[t]{10}{*}{ rs4783244 } & \multirow[t]{3}{*}{ Codominant } & $\mathrm{G} / \mathrm{G}$ & $66(45.2 \%)$ & $107(34.7 \%)$ & 1.00 & \multirow{3}{*}{0.017} & \multirow{3}{*}{601.5} & \multirow{3}{*}{832.1} \\
\hline & & $\mathrm{T} / \mathrm{G}$ & $63(43.1 \%)$ & $149(48.4 \%)$ & $1.40(0.86-2.29)$ & & & \\
\hline & & $\mathrm{T} / \mathrm{T}$ & $17(11.6 \%)$ & $52(16.9 \%)$ & $2.91(1.35-6.30)$ & & & \\
\hline & \multirow[t]{2}{*}{ Dominant } & $\mathrm{G} / \mathrm{G}$ & $66(45.2 \%)$ & $107(34.7 \%)$ & 1.00 & \multirow{2}{*}{0.037} & 6033 & 8208 \\
\hline & & $\mathrm{T} / \mathrm{G}-\mathrm{T} / \mathrm{T}$ & $80(54.8 \%)$ & $201(65.3 \%)$ & $1.64(1.03-2.62)$ & & ני.50 & 029.0 \\
\hline & Recessive & G/G-T/G & $129(88.4 \%)$ & $256(83.1 \%)$ & 1.00 & 2012 & 6013 & 8278 \\
\hline & & $\mathrm{T} / \mathrm{T}$ & $17(11.6 \%)$ & $52(16.9 \%)$ & $2.41(1.17-4.97)$ & 0.012 & J & 021.0 \\
\hline & Overdominant & $\mathrm{G} / \mathrm{G}-\mathrm{T} / \mathrm{T}$ & $83(56.9 \%)$ & $159(51.6 \%)$ & 1.00 & 0.760 & 607.5 & 834.0 \\
\hline & & $\mathrm{T} / \mathrm{G}$ & $63(43.1 \%)$ & $149(48.4 \%)$ & $1.07(0.68-1.69)$ & & & \\
\hline & Log-additive & --- & --- & --- & $1.61(1.14-2.27)$ & 0.006 & 600.0 & 826.5 \\
\hline rs12051272 & Codominant & $\mathrm{G} / \mathrm{G}$ & $71(48.6 \%)$ & $118(38.3 \%)$ & 1.00 & & & \\
\hline & & $\mathrm{G} / \mathrm{T}$ & $59(40.4 \%)$ & $142(46.1 \%)$ & $1.47(0.91-2.38)$ & 0.015 & 601.2 & 831.9 \\
\hline & & $\mathrm{T} / \mathrm{T}$ & $16(11.0 \%)$ & $48(15.6 \%)$ & $2.96(1.34-6.51)$ & & & \\
\hline & Dominant & $\mathrm{G} / \mathrm{G}$ & $71(48.6 \%)$ & $118(38.3 \%)$ & 1.00 & 0024 & 6025 & 8200 \\
\hline & & G/T-T/T & $75(51.4 \%)$ & $190(61.7 \%)$ & $1.69(1.07-2.69)$ & 0.024 & 002.5 & 029.0 \\
\hline & Recessive & G/G-G/T & $130(89.0 \%)$ & $260(84.4 \%)$ & 1.00 & 0015 & 6017 & $820 ?$ \\
\hline & & $\mathrm{T} / \mathrm{T}$ & $16(11.0 \%)$ & $48(15.6 \%)$ & $2.41(1.14-5.08)$ & 0.013 & O001.1 & 020.2 \\
\hline & Overdominant & $\mathrm{G} / \mathrm{G}-\mathrm{T} / \mathrm{T}$ & $87(59.6 \%)$ & $166(53.9 \%)$ & 1.00 & 0550 & $607 ?$ & 8337 \\
\hline & & $\mathrm{G} / \mathrm{T}$ & $59(40.4 \%)$ & $142(46.1 \%)$ & $1.15(0.73-1.81)$ & 0.040 & & \\
\hline & Log-additive & --- & --- & --- & $1.63(1.15-2.30)$ & 0.005 & 599.6 & 826.1 \\
\hline rs 7195409 & Codominant & $\mathrm{A} / \mathrm{A}$ & $87(60.0 \%)$ & $227(73.7 \%)$ & 1.00 & & & \\
\hline & & $\mathrm{A} / \mathrm{G}$ & $54(37.2 \%)$ & $75(24.4 \%)$ & $0.46(0.28-0.75)$ & 0.005 & 599.1 & 829.6 \\
\hline & & $\mathrm{G} / \mathrm{G}$ & $4(2.8 \%)$ & $6(2.0 \%)$ & $0.37(0.09-1.64)$ & & & \\
\hline & Dominant & $\mathrm{A} / \mathrm{A}$ & $87(60.0 \%)$ & $227(73.7 \%)$ & 1.00 & 0001 & 5972 & 8236 \\
\hline & & A/G-G/G & $58(40.0 \%)$ & $81(26.3 \%)$ & $0.45(0.28-0.73)$ & 0.001 & 201.20 & 025.0 \\
\hline & Recessive & $\mathrm{A} / \mathrm{A}-\mathrm{A} / \mathrm{G}$ & $141(97.2 \%)$ & $302(98.0 \%)$ & 1.00 & 0360 & 6068 & 8332 \\
\hline & & $\mathrm{G} / \mathrm{G}$ & $4(2.8 \%)$ & $6(2.0 \%)$ & $0.50(0.12-2.16)$ & & & \\
\hline & Overdominant & A/A-G/G & $91(62.8 \%)$ & $233(75.7 \%)$ & 1.00 & 0003 & 5087 & 8251 \\
\hline & & $\mathrm{A} / \mathrm{G}$ & $54(37.2 \%)$ & $75(24.4 \%)$ & $0.48(0.29-0.78)$ & 0.003 & 390.1 & 025.1 \\
\hline & Log-additive & --- & --- & --- & $0.50(0.32-0.77)$ & 0.002 & 597.6 & 823.9 \\
\hline
\end{tabular}

* Statistical significant threshold was set at $P<0.007$ (0.05/7) determined by Bonferroni correction.

cycles. Data acquisitions and analysis were performed on QuantStudio ${ }^{\mathrm{TM}}$ real-time PCR software. To identify the accuracy of SNP genotyping using the TaqMan assay, samples with each genotype of the seven SNPs were sequenced.

\section{Statistical analysis}

Microsoft Excel software and the SPSS 19.0 statistical package (SPSS, Chicago, IL, USA) were used to perform statistical analyses. Both the NSCLC and control 
groups were evaluated by Hardy-Weinberg equilibrium (HWE) for representativeness. The linkage disequilibrium (LD) having a D'/R2 value greater than $0.85 / 0.70$ was considered to be in linkage disequilibrium, and haplotypes were constructed based on the genotyping results by the expectation-maximization algorithm in SHEsis software $[52,53]$. The effects of the polymorphisms on the risk of NSCLC were expressed as ORs with $95 \% \mathrm{CI}$, which were calculated using logistic regression analysis with adjustment for age and gender. The association between each genotype and the risk of NSCLC was assessed using inheritance model analysis of SNPstats software [54]. Five inheritance models were analyzed including Codominant, Dominant, Recessive, Overdominant and Log-additive (https://www.snpstats.net/snpstats/tutorial. $\mathrm{htm}$ ? $\mathrm{q}=$ snpstats/tutorial.htm). Codominant model: this model allows every genotype to give a different and no additive risk., which compares heterozygous T/C $(\mathrm{He})$ and homozygous for the variant allele $\mathrm{C} / \mathrm{C}(\mathrm{Va})$ genotypes to the homozygous for the most frequent allele $\mathrm{T} / \mathrm{T}$. Dominant model: a single copy of $\mathrm{C}$ is enough to modify the risk, then heterozygous and homozygous genotypes have the same risk. Thus, we could compare a combination of these two possible genotypes $\mathrm{T} / \mathrm{C}+\mathrm{C} / \mathrm{C}$ (Do) to the homozygous T/T. Recessive model: two copies of $\mathrm{C}$ are necessary to change the risk. Hence, $\mathrm{T} / \mathrm{C}$ and $\mathrm{T} / \mathrm{T}$ genotypes have the same effect. A combination of both T/ $\mathrm{T}+\mathrm{T} / \mathrm{C}(\mathrm{Re})$ is compared to the variant allele homozygous genotype $\mathrm{C} / \mathrm{C}$. Over-dominant model: heterozygous are compared to a pool of both allele homozygous, the $\mathrm{T} / \mathrm{C}(\mathrm{He})$ is compared versus $\mathrm{T} / \mathrm{T}+\mathrm{C} / \mathrm{C}$. Additive model: each copy of $\mathrm{C}$ modifies the risk in an additive form, the homozygous $\mathrm{C} / \mathrm{C}$ have double risk than heterozygous $\mathrm{T} / \mathrm{C}$. Now, compare a combination of the two genotypes with weights 2 and 1 respectively $2 \mathrm{C} / \mathrm{C}+\mathrm{T} / \mathrm{C}(\mathrm{Ad})$, to $\mathrm{T} / \mathrm{T}$. The AIC and BIC were calculated to determine the best fit model for each SNP. The statistical power was calculated using PS Software [55]. Bonferroni correction was performed on the $P$ values for multiple comparison in the current study, and the statistical significant threshold was set at $P<0.007(0.05 / 7)$.

\section{CONCLUSIONS}

Several studies have demonstrated the association of SNPs in $C D H 13$ gene with the methylation of the CDH13 gene and circulating adiponectin levels, which might be used as the diagnostic and prognostic biomarker for NSCLC [22]. In the current study, we found that the T allele of rs11646213 in CDH13 might be the risk factor for NSCLC. The SNPs rs7195409 was associated with NSCLC pathologic stages. However, there were some limitations affecting the identification or association of SNPs with NSCLC in the current study. One of the limitations was the relatively modest sample size with a statistical power of only
$75.9 \%$. Another limitation was the lack of smoking status data for the control individuals, which made it difficult to perform further analyses of such exposure variables and to perform a gene-smoking interaction analysis in the current study. To clarify the association of $C D H 13$ variations with NSCLC susceptibility, larger scale samples and systemic studies that focus on the association of the SNPs in CDH13 gene with the methylation status, serum adiponectin levels and NSCLC susceptibility are needed in the future

\section{ACKNOWLEDGMENTS AND FUNDING}

This study was supported by the National Natural Science Foundation of China (81573206 and 31270030), Yunnan Applied Basic Research Projects (2016FA034), Special Funds for high-level health talents of Yunnan Province (D-201669 and L-201615), the Association Foundation Program of the Yunnan Provincial Science, Technology Department and Kunming Medical University (No.2017FE468-193) and CAMS Innovation Fund for Medical Sciences (2016-12M-2-001). We express our gratitude to all of our patients and healthy control volunteers for kindly donating their blood and their agreement to participate in this study.

\section{CONFLICTS OF INTEREST}

There are no conflicts of interest.

\section{REFERENCES}

1. McGuire S. World Cancer Report 2014. Geneva, Switzerland: World Health Organization, International Agency for Research on Cancer, WHO Press, 2015. Adv Nutr. 2016; 7:418-9. https://doi.org/10.3945/an.116.012211.

2. Zheng R, Zeng H, Zhang S, Chen W. Estimates of cancer incidence and mortality in China, 2013. Chin J Cancer. 2017; 36:66. https://doi.org/10.1186/s40880-017-0234-3.

3. Johnson JL, Pillai S, Chellappan SP. Genetic and biochemical alterations in non-small cell lung cancer. Biochem Res Int. 2012; 2012:940405. https://doi.org/10.1155/2012/940405.

4. Drilon A, Sugita H, Sima CS, Zauderer M, Rudin CM, Kris MG, Rusch VW, Azzoli CG. A prospective study of tumor suppressor gene methylation as a prognostic biomarker in surgically resected stage I to IIIA non-small-cell lung cancers. J Thorac Oncol. 2014; 9:1272-7. https://doi. org/10.1097/jto.0000000000000256.

5. Celebiler Cavusoglu A, Kilic Y, Saydam S, Canda T, Baskan Z, Sevinc AI, Sakizli M. Predicting invasive phenotype with CDH1, CDH13, CD44, and TIMP3 gene expression in primary breast cancer. Cancer Sci. 2009; 100:2341-5. https://doi.org/10.1111/j.1349-7006.2009.01333.x.

6. Kawakami M, Staub J, Cliby W, Hartmann L, Smith DI, Shridhar V. Involvement of H-cadherin (CDH13) on 16q 
in the region of frequent deletion in ovarian cancer. Int $\mathrm{J}$ Oncol. 1999; 15:715-20.

7. Morisaki H, Yamanaka I, Iwai N, Miyamoto Y, Kokubo Y, Okamura T, Okayama A, Morisaki T. CDH13 gene coding T-cadherin influences variations in plasma adiponectin levels in the Japanese population. Hum Mutat. 2012; 33:402-10. https://doi.org/10.1002/humu.21652.

8. Chung CM, Lin TH, Chen JW, Leu HB, Yang HC, Ho HY, Ting CT, Sheu SH, Tsai WC, Chen JH, Lin SJ, Chen YT, Pan WH. A genome-wide association study reveals a quantitative trait locus of adiponectin on CDH13 that predicts cardiometabolic outcomes. Diabetes. 2011; 60:2417-23. https://doi.org/10.2337/db10-1321.

9. Takeuchi T, Ohtsuki Y. Recent progress in T-cadherin (CDH13, H-cadherin) research. Histol Histopathol. 2001; 16:1287-93.

10. Stemmler MP. Cadherins in development and cancer. Mol Biosyst. 2008; 4:835-50. https://doi.org/10.1039/b719215k.

11. Lin YL, He ZK, Li ZG, Guan TY. Downregulation of CDH13 expression promotes invasiveness of bladder transitional cell carcinoma. Urol Int. 2013; 90:225-32. https://doi.org/10.1159/000345054.

12. Jin Z, Cheng Y, Olaru A, Kan T, Yang J, Paun B, Ito T, Hamilton JP, David S, Agarwal R, Selaru FM, Sato F, Abraham JM, et al. Promoter hypermethylation of CDH13 is a common, early event in human esophageal adenocarcinogenesis and correlates with clinical risk factors. Int $\mathrm{J}$ Cancer. 2008; 123:2331-6. https://doi. org/10.1002/ijc.23804.

13. Hibi K, Kodera Y, Ito K, Akiyama S, Nakao A. Methylation pattern of $\mathrm{CDH} 13$ gene in digestive tract cancers. Br J Cancer. 2004; 91:1139-42. https://doi.org/10.1038/sj.bjc.6602095.

14. Toyooka KO, Toyooka S, Virmani AK, Sathyanarayana UG, Euhus DM, Gilcrease M, Minna JD, Gazdar AF. Loss of expression and aberrant methylation of the CDH13 (H-cadherin) gene in breast and lung carcinomas. Cancer Res. 2001; 61:4556-60.

15. Putku M, Kals M, Inno R, Kasela S, Org E, Kozich V, Milani L, Laan M. CDH13 promoter SNPs with pleiotropic effect on cardiometabolic parameters represent methylation QTLs. Hum Genet. 2015; 134:291-303. https://doi. org/10.1007/s00439-014-1521-6.

16. Kerenidi T, Lada M, Tsaroucha A, Georgoulias P, Mystridou $\mathrm{P}$, Gourgoulianis KI. Clinical significance of serum adipokines levels in lung cancer. Med Oncol. 2013; 30:507. https://doi.org/10.1007/s12032-013-0507-x.

17. Li Y, Li C, Yang Y, Shi L, Tao W, Liu S, Yang M, Li X, Yao Y, Xiao C. The association of six single nucleotide polymorphisms and their haplotypes in CDH13 with T2DM in a Han Chinese population. Medicine (Baltimore). 2017; 96:e7063. https://doi.org/10.1097/md.0000000000007063.

18. Chen L, Sun KX, Juan J, Fang K, Liu K, Wang XY, Wang L, Yang C, Liu XQ, Li J, Tang X, Wu YQ, Qin XY, et al. CDH13 Genetic Polymorphisms, Adiponectin and Ischemic Stroke: a
Chinese Family-based Sib-pair Study. Biomed Environ Sci. 2017; 30:35-43. https://doi.org/10.3967/bes2017.004.

19. Park J, Kim I, Jung KJ, Kim S, Jee SH, Yoon SK. Genegene interaction analysis identifies a new genetic risk factor for colorectal cancer. J Biomed Sci. 2015; 22:73. https://doi. org/10.1186/s12929-015-0180-9.

20. Jemal A, Thun M, Yu XQ, Hartman AM, Cokkinides V, Center MM, Ross H, Ward EM. Changes in smoking prevalence among U.S. adults by state and region: Estimates from the Tobacco Use Supplement to the Current Population Survey, 1992-2007. BMC Public Health. 2011; 11:512. https://doi.org/10.1186/1471-2458-11-512.

21. Field JK, Hansell DM, Duffy SW, Baldwin DR. CT screening for lung cancer: countdown to implementation. Lancet Oncol. 2013; 14:e591-600. https://doi.org/10.1016/ s1470-2045(13)70293-6.

22. Boura P, Loukides S, Grapsa D, Achimastos A, Syrigos $\mathrm{K}$. The diverse roles of adiponectin in non-small-cell lung cancer: current data and future perspectives. Future Oncol. 2015; 11:2193-203. https://doi.org/10.2217/fon.15.96.

23. Jamieson NB, Brown DJ, Michael Wallace A, McMillan DC. Adiponectin and the systemic inflammatory response in weight-losing patients with non-small cell lung cancer. Cytokine. 2004; 27:90-2. https://doi.org/10.1016/j. cyto.2004.03.017.

24. Wang BH, Li YY, Han JZ, Zhou LY, Lv YQ, Zhang HL, Zhao L. Gene methylation as a powerful biomarker for detection and screening of non-small cell lung cancer in blood. Oncotarget. 2017; 8:31692-704. https://doi. org/10.18632/oncotarget.15919.

25. Petridou ET, Mitsiades N, Gialamas S, Angelopoulos M, Skalkidou A, Dessypris N, Hsi A, Lazaris N, Polyzos A, Syrigos C, Brennan AM, Tseleni-Balafouta S, Mantzoros CS. Circulating adiponectin levels and expression of adiponectin receptors in relation to lung cancer: two casecontrol studies. Oncology. 2007; 73:261-9. https://doi. org/10.1159/000127424.

26. Cust AE, Kaaks R, Friedenreich C, Bonnet F, Laville M, Lukanova A, Rinaldi S, Dossus L, Slimani N, Lundin E, Tjonneland A, Olsen A, Overvad K, et al. Plasma adiponectin levels and endometrial cancer risk in pre- and postmenopausal women. J Clin Endocrinol Metab. 2007; 92:255-63. https://doi.org/10.1210/jc.2006-1371.

27. Spyridopoulos TN, Petridou ET, Skalkidou A, Dessypris N, Chrousos GP, Mantzoros CS; Obesity and Cancer Oncology Group. Low adiponectin levels are associated with renal cell carcinoma: a case-control study. Int J Cancer. 2007; 120:1573-8. https://doi.org/10.1002/ijc.22526.

28. Wei EK, Giovannucci E, Fuchs CS, Willett WC, Mantzoros CS. Low plasma adiponectin levels and risk of colorectal cancer in men: a prospective study. J Natl Cancer Inst. 2005; 97:1688-94. https://doi.org/10.1093/jnci/dji376.

29. Tworoger SS, Eliassen AH, Kelesidis T, Colditz GA, Willett WC, Mantzoros CS, Hankinson SE. Plasma adiponectin 
concentrations and risk of incident breast cancer. J Clin Endocrinol Metab. 2007; 92:1510-6. https://doi. org/10.1210/jc.2006-1975.

30. Wei T, Ye P, Peng X, Wu LL, Yu GY. Circulating adiponectin levels in various malignancies: an updated meta-analysis of 107 studies. Oncotarget. 2016; 7:4867191. https://doi.org/10.18632/oncotarget.8932.

31. Wu Y, Li Y, Lange EM, Croteau-Chonka DC, Kuzawa CW, McDade TW, Qin L, Curocichin G, Borja JB, Lange LA, Adair LS, Mohlke KL. Genome-wide association study for adiponectin levels in Filipino women identifies CDH13 and a novel uncommon haplotype at KNG1-ADIPOQ. Hum Mol Genet. 2010; 19:4955-64. https://doi.org/10.1093/hmg/ ddq423.

32. Jee SH, Sull JW, Lee JE, Shin C, Park J, Kimm H, Cho EY, Shin ES, Yun JE, Park JW, Kim SY, Lee SJ, Jee EJ, et al. Adiponectin concentrations: a genome-wide association study. Am J Hum Genet. 2010; 87:545-52. https://doi. org/10.1016/j.ajhg.2010.09.004.

33. Wu Y, Gao H, Li H, Tabara Y, Nakatochi M, Chiu YF, Park EJ, Wen W, Adair LS, Borja JB, Cai Q, Chang YC, Chen P, et al. A meta-analysis of genome-wide association studies for adiponectin levels in East Asians identifies a novel locus near WDR11-FGFR2. Hum Mol Genet. 2014; 23:1108-19. https://doi.org/10.1093/hmg/ddt488.

34. Nicolas A, Aubert R, Bellili-Munoz N, Balkau B, Bonnet F, Tichet J, Velho G, Marre M, Roussel R, Fumeron F. T-cadherin gene variants are associated with type 2 diabetes and the Fatty Liver Index in the French population. Diabetes Metab. 2017; 43:33-9. https://doi.org/ 10.1016/j. diabet.2016.05.005.

35. Ling H, Waterworth DM, Stirnadel HA, Pollin TI, Barter PJ, Kesaniemi YA, Mahley RW, McPherson R, Waeber G, Bersot TP, Cohen JC, Grundy SM, Mooser VE, et al. Genome-wide linkage and association analyses to identify genes influencing adiponectin levels: the GEMS Study. Obesity (Silver Spring). 2009; 17:737-44. https://doi. org/10.1038/oby.2008.625.

36. Lee SW. H-cadherin, a novel cadherin with growth inhibitory functions and diminished expression in human breast cancer. Nat Med. 1996; 2:776-82.

37. Zhong Y, Delgado Y, Gomez J, Lee SW, Perez-Soler R. Loss of $\mathrm{H}$-cadherin protein expression in human non-small cell lung cancer is associated with tumorigenicity. Clin Cancer Res. 2001; 7:1683-7.

38. Lee SW, Reimer CL, Campbell DB, Cheresh P, Duda $\mathrm{RB}$, Kocher $\mathrm{O}$. H-cadherin expression inhibits in vitro invasiveness and tumor formation in vivo. Carcinogenesis. 1998; 19:1157-9.

39. Chan DW, Lee JM, Chan PC, Ng IO. Genetic and epigenetic inactivation of T-cadherin in human hepatocellular carcinoma cells. Int J Cancer. 2008; 123:1043-52. https:// doi.org/10.1002/ijc.23634.

40. Ye M, Huang T, Li J, Zhou C, Yang P, Ni C, Chen S. Role of $\mathrm{CDH} 13$ promoter methylation in the carcinogenesis, progression, and prognosis of colorectal cancer: A systematic meta-analysis under PRISMA guidelines. Medicine (Baltimore). 2017; 96:e5956. https://doi. org/10.1097/md.0000000000005956.

41. Liu B, Song J, Luan J, Sun X, Bai J, Wang H, Li A, Zhang L, Feng X, Du Z. Promoter methylation status of tumor suppressor genes and inhibition of expression of DNA methyltransferase 1 in non-small cell lung cancer. Exp Biol Med (Maywood). 2016; 241:1531-9. https://doi. org/10.1177/1535370216645211.

42. Feng W, Orlandi R, Zhao N, Carcangiu ML, Tagliabue E, Xu J, Bast RC Jr, Yu Y. Tumor suppressor genes are frequently methylated in lymph node metastases of breast cancers. BMC Cancer. 2010; 10:378. https://doi. org/10.1186/1471-2407-10-378.

43. Ozdemir F, Altinisik J, Karateke A, Coksuer H, Buyru N. Methylation of tumor suppressor genes in ovarian cancer. Exp Ther Med. 2012; 4:1092-6. https://doi.org/10.3892/ etm.2012.715.

44. Soozangar N, Sadeghi MR, Jeddi F, Somi MH, Shirmohamadi M, Samadi N. Comparison of genomewide analysis techniques to DNA methylation analysis in human cancer. J Cell Physiol. 2017. https://doi.org/10.1002/ jcp.26176.

45. Zhu C, Feng X, Ye G, Huang T. Meta-analysis of possible role of cadherin gene methylation in evolution and prognosis of hepatocellular carcinoma with a PRISMA guideline. Medicine (Baltimore). 2017; 96:e6650. https:// doi.org/ 10.1097/md.0000000000006650.

46. Abudukadeer A, Bakry R, Goebel G, Mutz-Dehbalaie I, Widschwendter A, Bonn GK, Fiegl H. Clinical relevance of CDH1 and CDH13 DNA-methylation in serum of cervical cancer patients. Int J Mol Sci. 2012; 13:8353-63. https:// doi.org/10.3390/ijms13078353.

47. Yang J, Niu H, Huang Y, Yang K. A Systematic Analysis of the Relationship of CDH13 Promoter Methylation and Breast Cancer Risk and Prognosis. PLoS One. 2016; 11:e0149185. https://doi.org/10.1371/journal.pone.0149185.

48. Jin X, Liu X. Integrated Analysis of DNA Methylation and mRNA Expression Profiles Data to Identify Key Genes in Lung Adenocarcinoma. 2016; 2016:4369431. https://doi. org/10.1155/2016/4369431.

49. Shi J, Marconett CN, Duan J, Hyland PL, Li P, Wang Z, Wheeler W, Zhou B, Campan M, Lee DS, Huang J, Zhou $\mathrm{W}$, Triche $\mathrm{T}$, et al. Characterizing the genetic basis of methylome diversity in histologically normal human lung tissue. Nat Commun. 2014; 5:3365. https://doi.org/10.1038/ ncomms4365.

50. Zhi D, Aslibekyan S, Irvin MR, Claas SA, Borecki IB, Ordovas JM, Absher DM, Arnett DK. SNPs located at CpG sites modulate genome-epigenome interaction. Epigenetics. 2013; 8:802-6. https://doi.org/10.4161/epi.25501.

51. Groome PA, Bolejack V, Crowley JJ, Kennedy C, Krasnik M, Sobin LH, Goldstraw P; IASLC International Staging 
Committee; Cancer Research and Biostatistics; Observers to the Committee; Participating Institutions. The IASLC Lung Cancer Staging Project: validation of the proposals for revision of the $\mathrm{T}, \mathrm{N}$, and $\mathrm{M}$ descriptors and consequent stage groupings in the forthcoming (seventh) edition of the TNM classification of malignant tumours. J Thorac Oncol. 2007; 2:694-705. https://doi.org/10.1097/JTO.0b013e31812d05d5.

52. Li Z, Zhang Z, He Z, Tang W, Li T, Zeng Z, He L, Shi Y. A partition-ligation-combination-subdivision EM algorithm for haplotype inference with multiallelic markers: update of the SHEsis (http://analysis.bio-x.cn). Cell Res. 2009; 19:519-23. https://doi.org/10.1038/cr.2009.33.
53. Shi YY, He L. SHEsis, a powerful software platform for analyses of linkage disequilibrium, haplotype construction, and genetic association at polymorphism loci. Cell Res. 2005; 15:97-8. https://doi.org/10.1038/sj.cr.7290272.

54. Sole X, Guino E, Valls J, Iniesta R, Moreno V. SNPStats: a web tool for the analysis of association studies. Bioinformatics. 2006; 22:1928-9. https://doi.org/10.1093/ bioinformatics/btl268.

55. Dupont WD, Plummer WD Jr. Power and sample size calculations for studies involving linear regression. Control Clin Trials. 1998; 19:589-601. 